\title{
ABSTRAK \\ FAKTO-FAKTOR YANG BERHUBUNGAN DENGAN RENDAHNYA PENGGUNAAN KONTRASEPSI JANGKA PANJANG DI WILAYAH KERJA PUSKESMAS ANREAPI KABUPATEN POLEWALI MANDAR
}

\author{
Martini $^{1}$, Niar $^{2}$, Teresia $\operatorname{Intan}^{3}$, Darmawati $^{4}$ \\ $(v+75$ halaman + 10lampiran $)$
}

Latar belakang :Kontrasepsi berasal dari kata kontra yang berarti mencegah atau melawan, konsepsi adalah pertemuan antara sel telur dan sel sperma yang mengakibatkan kehamilan. Dalam upaya untuk menurunkan atau mencegah tingkat kehamilan ada berbagai macam cara salah satunya menggunakan kontrasepsi jangka panjang.Menurut Prawirohardjo metode kontrasepsi jangka panjang merupakan jenis kontrasepsi yang sekali pemakaiannya dapat bertahan selam 3 tahun sampai seumur hidup, jenis kontrasepsi ini diantaranya adalah AKDR/IUD, implant, MOW dan MOP. Metode KB jangka panjang adalah alat kontrasepsi yang di gunakan untuk menunda kehamilan, serta menghentikan kesuburan, yang digunakan dengan jangka panjang, yang meliputi IUD (alat kontrasepsi rahim), implan dan kontrasepsi mantap.Menurut World Organization (WHO) keluarga berencana adalah mendapatkan objektif-objektif tertentu, menghindari kelahuran yang tak di inginkan, mengatur interval diantara kehamilan, mendapatkan kelahiran yang memang diingankan, mengontrol waktu saat kelahiran dalam hubungan dengan suami istri, menentukan jumlah anak dalam keluarga(Hartono,2014).

Tujuan : Tujuan dalam penelitian Untuk mengetehui faktor-faktor yang berhubungan dengan pengguna metode jangka panjang di Wilayah kerja Puskesmas Anreapi Kabupaten Polewali Mandar.

Metode Penelitian :Metode pengambilan di lakukan dengan random samplingsampling dengan 94 responden, pengumpulan data dengan menggunakan lembar kuesioner dan lembar cheklist.

Hasil : Hasil penelitian ini menunjukkan adanya hubungan antara pengetahuan, pendidikan, sosial ekonomi dan dukungan keluarga dengan rendahnya penggunaan MKJP di Wilayah kerja Puskesmas Anreapi Kabupaten Polewali Mandar.

Kesimpulan : Berdasarkan hasil penelitian ini Pentingnya usaha peningkatan pengetahuan PUS tentang MKJP. Usaha peningkatan ini dilakukan dengan melakukan penyuluhan di Puskesmas.

Kata Kunci : Kontrasepsi Jangka Panjang, Pasangan Usia Subur.

Daftar Pustaka : 14 buku (2008-2012) + 2 artikel dari internet dan 2 jurnal 


\title{
ABSTRACT \\ FACTIONS RELATED TO THE LOW USE OF LONG- TERMCONTRACEPTION IN THE WORKING AREA OF PUSKESMAS ANREAPIPOLEWALI MANDAR DISTRICT
}

\author{
Martini $^{1}$, Niar $^{2}$, Teresia $\operatorname{Intan}^{3}$, Darmawati $^{4}$ \\ (vi +75 page +10 attachments $)$
}

Background: Contraception comes from the word counter which means to prevent or fight, conception is the meeting between the egg and sperm cells which results in pregnancy. In an effort to reduce or prevent pregnancy rates there are various ways one of them uses long-term contraception. According to Prawirohardjo, long-term contraceptive method is a type of contraception that once used can last for 3 years to a lifetime, this type of contraception includes IUD / IUD, implants, MOW and MOP. Long-term family planning methods are contraceptives that are used to delay pregnancy, and stop fertility, which is used over the long term, which includes IUDs (uterine contraceptives), implants and solid contraception. According to the World Organization (WHO) family planning is gaining certain objectives, avoiding unwanted brawls, regulating intervals between pregnancies, getting births that are alleviated, controlling time at birth in relationships with husband and wife, determining the number of children in the family (Hartono, 2014)

Objective : objectives in the study To understand the factors associated with users of long-term methods in the Anreapi Community Health Center PolewaliMandar District

Research : Met The collection method was carried out with a random sampling sample with 94 respondents, data collection using questionnaire sheets and checklist.

Results : The results of this study indicate a relationship between knowledge, education, socio-economic and family support with the low use of MKJP in the Anreapi Health Center in Polewali District Mandar.

Conclusion : Based on the results of this study the importance of efforts to increase knowledge of EFA about MKJP. This improvement effort was carried out by conducting counseling at the health center.

Kywords :Use og long-term contraceptive, fertile age couples.

Bibliography : 14 book $(2008-2012)+2$ articles from the internet and 2 journals 


\section{PENDAHULUAN}

\section{Latar Belakang}

Kontrasepsi berasal dari kata kontra yang berarti mencegah atau melawan, konsepsi adalah pertemuan antara sel telur dan sel sperma yang mengakibatkan kehamilan. Dalam upaya untuk menurunkan atau mencegah tingkat kehamilan ada berbagai macam cara salah satunya menggunakan kontrasepsi jangka panjang.

Menurut Prawirohardjo metode kontrasepsi jangka panjang merupakan jenis kontrasepsi yang sekali pemakaiannya dapat bertahan selam 3 tahun sampai seumur hidup, jenis kontrasepsi ini diantaranya adalah AKDR/IUD, implant, MOW dan MOP (Prawirohardjo,Sarwono ,2014).

Adapun pengertian metode kontrasepsi jangka panjang menurut Hartanto yaitu tindakan yang membantu individu atau pasangan usia subur yang sangat efektif untuk menghindari kelahiran, mengatur interval kelahiran, dan tidak mempengaruhi hubungan seksual (Hartanto,Hanafi : 2013).

Metode KB jangka panjang adalah alat kontrasepsi yang di gunakan untuk menunda kehamilan, serta menghentikan kesuburan, yang digunakan dengan jangka panjang, yang meliputi IUD (alat kontrasepsi rahim), implan dan kontrasepsi mantap.

MenurutWorld Organization (WHO) keluarga berencana adalah mendapatkan objektifobjektif tertentu, menghindari kelahuran yang tak di inginkan, mengatur interval diantara kehamilan, mendapatkan kelahiran yang memang diingankan, mengontrol waktu saat kelahiran dalam hubungan dengan suami istri, menentukan jumlah anak dalam keluarga(Hartono,2014).

$$
\text { Padasaatini }
$$

di perkirakanmemakai AKDR/IUD, 30\% terdapat di Cina, $13 \%$ di Eropa, 5\% di Amerikadansekitar $\quad 6,7 \%$ di Negara-negaraberkembang (Augustin, 2000).

Di Indonesia merupakan negara yang terlihat dari jumlah penduduknya banyak, namun Badan Kependudukan dan Keluarga Berencana Nasional(BKKBN) mencatat penggunaan metode kontrasepsi jangka panjang menurun. Hasil survei demograsi dan kesehatan indonesia menunjukkan dari total peserta $\mathrm{KB}$ pada tahun 2016 sebanyak $16,4 \%$.

Program

Keluarga Berencana (KB) diIndonesia merupakan salah satu upaya dalam mengendalikan dan menurunkan laju pertumbuhan 
penduduk dengan cara meningkatkan angka prevalensi kontrasepsi. Salah satu indikator tercapainya program $\mathrm{KB}$ yaitu meningkatnya jumlah akseptor KB [1]. Setiap pasangan yang menggunakan kontrasepsi dilandasi permintaan $\mathrm{KB}$ yang jelas, baik untuk menunda kehamilan, mengatur jarak kehamilan atau tidak ingin punya anak lagi. Kejelasan maksud tersebut terkait dengan tersedianya teknologi kontrasepsi sesuai dengan keamanan medis serta kemungkinan kembalinya fase kesuburan, efektivitas, dan efisiensi metode kontrasepsi [2].

Berdasarkan laporan hasil mini survei, metode kontrasepsi yang paling dominan digunakan oleh Pasangan Usia Subur (PUS) baik di Indonesia maupun di Jawa Timur yaitu suntik dan pil yang termasuk dalam kategori non MKJP, sedangkan tujuan ber-KB pada PUS paling banyak yaitu membatasi kelahiran [3]. Hal tersebut menunjukkan bahwa pemakaian alat kontrasepsi pada PUS di Indonesia tidak sesuai dengan permintaan KB-nya. Permintaan KB dipengaruhi beberapa faktor yaitu akses yang terdiri dari sumber pelayanan dan biaya yang dikeluarkan; nilai anak dan keinginan anak; faktor sosial yang terdiri dari status ekonomi dan tempat tinggal; serta faktor individu meliputi umur dan pendidikan [2].

Permintaan dipengaruhi oleh paritas yaitu PUS yang bertujuan membatasi kehamilan paling besar di antara perempuan pada paritas empat [4]. Permintaan KB sangat terkait dengan faktor sosial dan budaya berupa tingkat pendidikan, pendapatan keluarga, status pekerjaan dan tingkat pembangunan suatu daerah [5]. Permintaan KB yang rasional dibagi menjadi tiga tahap yaitu menunda kehamilan, menjarangkan kehamilan dan membatasi kehamilan.

Maksud kebijakan tersebut yaitu untuk menyelamatkan ibu dan anak akibat melahirkan pada usia muda, jarak kelahiran yang terlalu dekat dan melahirkan pada usia tua. Permintaan KB untuk menunda kehamilan bagi PUS dengan usia istri kurang dari 20 tahun dianjurkan untuk menggunakan alat kontrasepsi pil yang temasuk dalam nonMKJP. Permintaan KB untuk menjarangkan kehamilan banyak terjadi pada saat usia istri antara 20-30 atau 35 tahun yang merupakan periode usia paling baik untuk melahirkan, dengan jumlah anak 2 orang dan jarak antar kehamilan adalah 2-4 tahun.Metode kontrasepsi yang tepat untuk digunakan yaitu 
kondom wanita, implan dan suntik.

Permintaan KB untuk menghentikan atau mengakhiri kehamilan lebih banyak terjadi pada istri yang berusia di atas 30 tahun dan tidak ingin mempunyai anak lagi. Metode kontrasepsi yang tepat yaitu kontrasepsi mantap (MOP atau MOW) dan IUD yang termasuk Metode Kontrasepsi Jangka Panjang (MKJP) [6]. sebagaimana hasil survei pada tingkat nasional maupun propinsi. Banyaknya PUS yang masih memakai alat kontrasepsi dengan metode non MKJP yang tidak disesuaikan dengan permintaan KB akan berdampak pada peningkatan fertilitas.

Makapemilihan alat kontrasepsi yang digunakan oleh akseptor hendaknya disesuaikan dengan permintaan $\mathrm{KB}$ agar tujuan ber-KB terpenuhi dan mencapai efektifitas yang tinggi. Oleh karena itu, peneliti ingin berinisiatif untuk menganalisis hubungan faktor demografi, sosio ekonomi dan akses pelayanan dengan permintaan $\mathrm{KB}$ dan kesesuaian penggunaan alat kontrasepsi, serta menganalisis permintaan $\mathrm{KB}$ dengan kesesuaian penggunaan alat kontrasepsi. (e-Jurnal Pustaka Kesehatan, vol. 3 (no. 1) Januari 2015
Terkait dengan hasil evaluasi penatalaksaan program KKBPK berdasarkan hasil evaluasi tenaga tahun BKKBN Pusat, dari 34 provensi capaian program KB provensi Sulawesi Barat berada pada urutan ke-3 dan dari segi persentase Metode Kontrasepsi Jangka Panjang (MKJP) Sulawesi Barat berada pada urutan pertama dari target pengguna MKJP 5,9\%. (KKBPK tahun2017).

Data dari

DinasKesehatanPolewali

Mandar pengguna alat kontrasepsi jangka panjang masih kurang. Hasil data pangguna kontrasepsi jangka panjang tahun 2016 tercatat $3,7 \%$ menggunakan kontrasepsi jangka panjang.

Data yang ada di Puskesmas Anreapi pengguna kontrasepsi jangka panjang menurundaritahun 2016, tercatatjumlah ibu yang menggunkan kontrasepsi IUD tercatat 4 orang, yang menggunakan Implant tercatat 164 orang, yang menggunakankontrasepsiMantap tercatat 3 orang, di tahun 2017 penggunakontrasepsijangkapanja ngmenurun, jumlahibu yang menggunakan IUD tercatat 3 orang, Implattercatan 120 orang, dan yang menggunkan kontrasepsimantaptercatat 1 orang. 


\section{METODOLOGI PENELITIAN}

\section{Rancangan Penelitian}

Penelitian adalah suatu usaha penyelidikan yang hatihati dan secara teratur terhadap suatu objek tertentu untuk memperoleh suatu kebenaran atau bakuti kebenaran. Penelitian ini menggunakan metode penelitian deskriptif yaitu suatu metode penelitian yang dilakukan dengan tujuan utama untuk membuat gambaran tentang suatu keadaan secara objektif yang digunakan untuk memecahkan atau menjawab permasalahan yang sedang dihadapi pada situasi sekarang. Penelitian deskriptif adalah penelitian diarahkan untuk mendeskripsikan atau menguraikan suatu keadaan di dalam suatu komunitas atau masyrakat (Natoatmodjo, 2010 :26).

Penelitian ini dilakukan untuk mendapatkan gambaran pengetahuan ibu hamil tentang susu ibu hamil di wilayah kerja Puskesmas Anreapi Kecamatan Anreapi Kabupaten Polewali Mandar.

\section{HASIL PENELITIAN DAN PEMBAHASAN}

\section{Analisa Univariat}

Distribusi Responden Berdasarkan Kelompok usia

\section{Tabel 4.1}

Distribusi Frekuensi Responden Menurut Kelompok Umur akseptor KB di wilayah kerja Puskesmas Anreapi Kecamatan Polewali Kabupaten Polewali MandarTahun 2018

\begin{tabular}{|c|c|c|c|}
\hline No & Umur & Frekuensi & Presentase \\
\hline 1 & $20-35$ & 66 & $70,2 \%$ \\
\hline 2 & $>35$ & 28 & $29,8 \%$ \\
\hline & Jumlah & 94 & $100 \%$ \\
\hline
\end{tabular}

Sumber : Data Primer

Berdasarkan tabel 4.1

tentang umur responden, dimana hasil penelitian menunjukkan bahwa dari 94 responden yang berusia 20 -
35 tahun sebanyak 66 responden atau ( $70,2 \%)$ dan yang berusia > 35 sebanyak 28 responden atau $(29,8 \%)$. 


\section{Distribusi Responden Berdasarkan Pengetahuan}

Tabel 4.2

Distribusi Frekuensi Responden Berdasarkan Pengetahuan akseptor KB di wilayah kerja Puskesmas Anreapi Kecamatan Polewali

Kabupaten Polewali MandarTahun 2018

\begin{tabular}{|c|c|c|c|}
\hline No & Pengetahuan & Frekuensi & Presentase \\
\hline 1 & Baik & 39 & $41,4 \%$ \\
\hline 2 & Kurang & 55 & $58,6 \%$ \\
\hline & Jumlah & 94 & $100 \%$ \\
\hline
\end{tabular}

Berdasarkan tabel 4.2 tentang Pengetahuan responden, dimana hasil penelitian menunjukkan bahwa dari 94 responden, yang berpengetahuan baik sebanyak 39 responden atau $(41,4 \%)$ dan yang berpengetahuan kurang sebanyak 55 responden atau $(58,6 \%)$.

\section{Distribusi Responden Berdasarkan Pendidikan}

\section{Tabel 4.3}

Distribusi Frekuensi Responden Berdasarkan Pendidikan akseptor KB di wilayah kerja Puskesmas Anreapi Kecamatan Polewali Kabupaten Polewali MandarTahun 2018

Sumber : Data Primer

\begin{tabular}{|c|c|c|c|}
\hline No & Pendidikan & Frekuensi & Presentase \\
\hline 1 & Dasar & 45 & $47,9 \%$ \\
\hline 2 & Menengah & 42 & $44,7 \%$ \\
\hline 3 & Tinggi & 7 & $7,4 \%$ \\
\hline & Jumlah & 94 & $100 \%$ \\
\hline
\end{tabular}

Berdasarkan tabel 4.3 tentang Pendidikan responden, dimana hasil penelitian menunjukkan bahwa dari 94 responden, yang responden dengan pendidikan rendah sebanyak 45 responden atau
(47,9\%), dengan pendidikan menengah sebanyak 42 responden atau $(44,7 \%)$ dan dengan pendidikan tinggi sebanyak 7 responden atau $(7,4 \%)$. 


\section{Distribusi Responden Berdasarkan Sosial ekonomi}

Tabel 4.4

Distribusi Frekuensi Responden Berdasarkan Sosial ekonomi akseptor KB di wilayah kerja Puskesmas Anreapi Kecamatan Polewali

Kabupaten Polewali MandarTahun 2018

\begin{tabular}{|c|c|c|c|}
\hline No & Sosial ekonomi & Frekuensi & Presentase \\
\hline 1 & Menengah ke atas & 53 & $56,3 \%$ \\
\hline 2 & Menengah ke bawah & 41 & $43,7 \%$ \\
\hline & Jumlah & 94 & $100 \%$ \\
\hline
\end{tabular}

Sumber : Data Primer

Berdasarkan tabel 4.4

tentang Sosial ekonomi responden, dimana hasil penelitian menunjukkan bahwa dari 94 responden, responden dengan sosial ekonomi menengah ke atas sebanyak 53 responden atau $(56,3 \%)$ dan responden dengan sosial ekonomi menengah ke bawah sebanyak 41 responden atau $(43,7 \%)$.

Distribusi Responden Berdasarkan Dukungan Keluarga

Tabel 4.5

Distribusi Frekuensi Responden Berdasarkan Dukungan Keluarga akseptor KB di wilayah kerja Puskesmas Anreapi Kecamatan Polewali Kabupaten Polewali MandarTahun 2018

\begin{tabular}{|c|c|c|c|}
\hline No & Dukungan Keluarga & Frekuensi & Presentase \\
\hline 1 & Mendukung & 43 & $45,8 \%$ \\
\hline 2 & Tidak mendukung & 51 & $54,2 \%$ \\
\hline & Jumlah & 94 & $100 \%$ \\
\hline
\end{tabular}

Sumber : Data Primer

Berdasarkan tabel 4.5 tentang Dukungan Keluarga responden, dimana hasil penelitian menunjukkan bahwa dari 94 responden, responden dengan keluarga yang mendukung sebanyak 43 responden atau $(45,8 \%)$ dan responden dengan keluarga yang tidak mendukung sebanyak 51 responden atau $(54,2 \%)$. 
Distribusi Responden Berdasarkan Penggunaan MKJP ( Metode Kontrasepsi Jangka Panjang )

Tabel 4.6

Distribusi Frekuensi Responden Penggunaan MKJP di wilayah kerja Puskesmas Anreapi Kecamatan Polewali Kabupaten Polewali Mandar Tahun 2018

\begin{tabular}{|c|c|c|c|}
\hline No & Penggunaan Kontrasepsi MKJP & Frekuensi & Presentase \\
\hline 1 & Menggunakan MKJP & 21 & $22,3 \%$ \\
\hline 2 & Tidak menggunakan MKJP & 73 & $77,7 \%$ \\
\hline & Jumlah & 94 & $100 \%$ \\
\hline
\end{tabular}

\section{Sumber : Data Primer}

Berdasarkan tabel 4.6 tentang Penggunaan MKJP responden, dimana hasil penelitian menunjukkan bahwa dari 94 responden, responden

yang menggunakan MKJP sebanyak 21 responden atau $(22,3$ $\%)$ dan responden yang tidak menggunakan MKJP sebanyak 73 responden atau $(77,7 \%)$.

\section{Analisa Bivariat}

Analisa Bivariat dalam penelitian ini adalah untuk mengidentifikasi faktor-faktor yang berhubungan dengan pengguna metode jangka panjang di Wilayah kerja Puskesmas Anreapi Kabupaten Polewali Mandar.

Hubungan antara umur dengan rendahnya penggunaan metode Kontrasepsi jangka panjang.

Tabel 4.7

Hubungan antara umur responden dengan rendahnya penggunaan metode kontrasepsi jangka Panjang (MKJP)

\begin{tabular}{|c|c|c|c|c|}
\hline \multirow{2}{*}{ Umur } & \multicolumn{2}{|c|}{ MKJP } & \multirow{2}{*}{ Total } & \multirow{2}{*}{ P } \\
\cline { 2 - 3 } & MKJP & Non MKJP & & \\
\hline $20-35$ & 16 & 50 & 66 & 0,497 \\
\hline
\end{tabular}




\begin{tabular}{|c|c|c|c|}
\hline$>35$ & 5 & 23 & 28 \\
\hline Total & 21 & 73 & 94 \\
\hline
\end{tabular}

Sumber : Data Primer

Distribusi responden berdasarkanHubungan antara umur dengan rendahnya penggunaan metode Kontrasepsi jangka panjang, responden dengan umur 20-35 dan menggunakan MKJP sebanyak 16 responden dan yang tidak menggunakan MKJP 50 responden sedangkan yang berumur $>35$ yang menggunakan MKJP 5 responden dan yang tidak menngunakan MKJP 23 responden.

Berdasarkan Chi-Square dengan nilai kemakmuran $\mathrm{a}=0,05$ dimana hasil peneliti diperoleh hasil $\mathrm{p}=0,497$ yang menunjukkan $\mathrm{p}>$ atau $0,497>0,05$ menunjukkan tidak ada hubungan antara tingkat umur dengan rendahnya penggunaan MKJP.

Hubungan antara Pengetahuan responden dengan rendahnya penggunaan metode Kontrasepsi jangka panjang.

Tabel 4.8

Hubungan antara Pengetahuan responden dengan rendahnya penggunaan metode kontrasepsi jangka Panjang (MKJP)

\begin{tabular}{|c|c|c|c|c|}
\hline \multirow{2}{*}{ Pengetahuan } & \multicolumn{2}{|c|}{ MKJP } & \multirow{2}{*}{ Total } & \multirow{2}{*}{$\mathbf{P}$} \\
\hline & MKJP & Non MKJP & & \\
\hline Baik & 11 & 28 & 39 & \multirow{3}{*}{0,250} \\
\hline Kurang & 10 & 45 & 55 & \\
\hline Total & 21 & 73 & 94 & \\
\hline
\end{tabular}

Sumber : Data Primer

Distribusi responden berdasarkan Hubungan antara Pengetahuan dengan rendahnya penggunaan metode Kontrasepsi jangka panjang, responden dengan pengetahuan baikmenggunakan MKJP sebanyak 11 responden, yang berpengetahuan kurang dan menggunakan MKJP 10 responden sedangkan responden dengan engetahuan baik yang tidak menggunakan MKJP 28 responden dan yang berpengetahuan buruk dan tidak menggunakan MKJP 45 responden.

Berdasarkan Chi-Square dengan nilai kemakmuran $\mathrm{a}=0,05$ dimana hasil peneliti diperoleh hasil $\mathrm{p}=0$,250yang menunjukkan $\mathrm{p}>$ atau 0,250>0,05 menunjukkan tidak ada hubungan antara tingkat Pengetahuan dengan rendahnya penggunaan MKJP. 
Hubungan antara Pendidikan responden dengan rendahnya penggunaanmetodeKontrasepsi jangka panjang.

Tabel 4.8

Hubungan antara Pendidikan responden dengan rendahnya penggunaan metode kontrasepsi jangka Panjang (MKJP)

\begin{tabular}{|c|c|c|c|c|}
\hline \multirow{2}{*}{ Pendidikan } & \multicolumn{2}{|c|}{ MKJP } & \multirow{2}{*}{ Total } & \multirow{2}{*}{ P } \\
\cline { 2 - 4 } & MKJP & Non MKJP & \\
\hline Dasar & 5 & 40 & 45 & \multirow{2}{*}{0,011} \\
\hline Menengah & 12 & 30 & 42 & \\
\hline Tinggi & 4 & 3 & 7 & \\
\hline Total & 21 & 73 & 94 & \\
\hline
\end{tabular}

Sumber : Data Primer

Distribusi responden berdasarkan Hubungan antara Pendidikan dengan rendahnya penggunaan metode Kontrasepsi jangka panjang, responden dengan Pendidkan dasar menggunakan MKJP 5 responden, menengah menggunakan MKJP 12 responden pendidikan tinggi menggunakan MKJP 4 responden sedangkan responden dengan pendidkan dasar tidak menggunakan MKJP 40 responden, $\quad$ pendidikan menengah tidak menggunakan MKJP 30 responden yang pendidikan tinggi tidak menggunakan MKJP 3 responden.

Berdasarkan Chi-Square dengan nilai kemakmuran $\mathrm{a}=0,05$ dimana hasil peneliti diperoleh hasil $\mathrm{p}=0,011$ yang menunjukka $\mathrm{p}<$ atau $0,011<$ 0,05 menunjukkan ada hubungan antara tingkat Pendidikan dengan rendahnya penggunaan MKJP.

Hubungan antara Sosial ekonomi responden dengan rendahnyapenggunaan metode Kontrasepsi jangka panjang. 
Tabel 4.9

Hubungan antara Sosial ekonomi responden dengan rendahnya penggunaan metode kontrasepsi jangka Panjang (MKJP)

\begin{tabular}{|c|c|c|c|c|}
\hline \multirow{2}{*}{ Sosial ekonomi } & \multicolumn{2}{|c|}{ MKJP } & \multirow{2}{*}{ Total } & \multirow{2}{*}{ P } \\
\cline { 2 - 4 } & MKJP & Non MKJP & \\
\hline Menengah ke atas & 16 & 37 & 53 & \multirow{2}{*}{0,038} \\
\hline Menengah ke bawah & 5 & 36 & 41 & \\
\hline Total & 21 & 73 & 94 & \\
\hline
\end{tabular}

Sumber : Data Primer

Distribusi responden bawah menggunakan MKJP 5 berdasarkan Hubungan antara responden dan yang tidak Pendidikan dengan rendahnya menggunakan MKJP 36 responden. penggunaan metode Kontrasepsi Berdasarkan Chi-Square dengan nilai jangka panjang, responden dengan kemakmuran $\mathrm{a}=0,05$ dimana hasil sosial ekonomi menengah $\mathrm{ke}$ atas peneliti diperoleh hasil $\mathrm{p}=0,038 \mathrm{yang}$ menggunakan MKJP 16 responden menunjukka $\mathrm{p}<$ atau $0,038<0,05$ yang tidak menggunakan MKJP 37 menunjukkan ada hubungan antara responden sedangkan responden tingkat Sosial ekonomi dengan dengan sosial ekonomi menengah ke rendahnya penggunaan MKJP.

Hubungan antara Dukungan keluarga responden dengan rendahnya penggunaan metode Kontrasepsi jangka panjang.

Tabel 4.10

Hubungan antara Dukungan keluarga responden dengan rendahnya penggunaanmetode kontrasepsi jangka Panjang (MKJP)

\begin{tabular}{|c|c|c|c|c|}
\hline \multirow{2}{*}{ Dukungan keluarga } & \multicolumn{2}{|c|}{ MKJP } & \multirow{2}{*}{ Total } & \multirow{2}{*}{ P } \\
\cline { 2 - 4 } & MKJP & Non MKJP & & \\
\hline Mendukung & 16 & 27 & 43 & \multirow{2}{*}{0,001} \\
\hline Tidak Mendukung & 5 & 46 & 51 & \\
\hline Total & 21 & 73 & 94 \\
\hline
\end{tabular}

Sumber : Data Primer 


\begin{abstract}
Distribusi responden
berdasarkan Hubungan antara

Pendidikan dengan rendahnya

penggunaan metode Kontrasepsi jangka panjang, responden dengan keluarga yang mendukung dan menggunakan MKJP 16 responden, keluarga mendukung dan tidak menggunakan MKJP 27 responden sedangkan responden dengan keluarga yang tidak mendukung dan
\end{abstract}

Pembahasan

\section{Hubungan antara umur dengan rendahnya penggunaan metodeKontrasepsi jangka panjang.}

Usia dewasa awal merupakan usia bagi seseorang untuk dapat memotivasi diri memperoleh pengetahuan sebanyak banyaknya. Usia adalah lamanya hidup seseorang dari sejak lahir yang dinyatakan dengan tahun. Usia mempengaruhi terhadap daya tangkap dan pola pikir seseorang.

Semakin bertambah usia akan semakin berkembang pula daya tangkap dan pola pikirnya, sehingga pengetahuan yang diperolehnya semakin membaik. Individu akan lebih berperan aktif dalam masyarakat dan kehidupan sosial serta lebih banyak melakukan persiapan menuju usia tua saat menginjak usia dewasa.

Jadi semakin matang usia seseorang, maka dalam memahami suatu masalah akan lebih mudah dan menggunakan MKJP 5 responden dan yang tidak menggunakan MKJP 46 responden.

Berdasarkan Chi-Square dengan nilai kemakmuran $a=0,05$ dimana hasil peneliti diperoleh hasil $\mathrm{p}=0,001$ yang menunjukka $\mathrm{p}<$ atau $0,001<0,05$ menunjukkan ada hubungan antara dukungan keluarga dengan rendahnya penggunaan MKJP.

dapat menambah pengetahuan. Semakin tua seseorang maka akan mempunyai kesempatan dan waktu yang lebih lama dalam mendapatkan informasi dan pengetahuan. Semakin tua umur responden asalkan dalam batasan reproduktif maka tingkat pengetahuan seseorang tentang sesuatu hal akan semakin baik.

$$
\text { Pada kelompok responden }
$$

yang berumur tua (>35 tahun) sebagian besar menggunakan MKJP (50\%) dibandingkan dengan kelompok responden yang berumur muda $(<30$ tahun) yaitu hanya sebesar $11,1 \%$.

Hasil Bivariat menunjukkan tidak ada hubungan antara umur dengan rendahnya penggunaan metode Kontrasepsi jangka panjang, dimana hasil uji Chi- square dengan nilai kemakmuran $\mathrm{a}=0,05$ dimana hasil $\mathrm{p}=0,497$ yang menunjukkan $\mathrm{p}$ $>$ atau 0, 497 > 0,05 menunjukkan tidak ada hubungan antara tingkat umur dengan rendahnya penggunaan MKJP. 
Penelitian ini menunjukkan tidak ada hubungan umur dengan rendahnya penggunaan metode Kontrasepsi jangka panjang dimana dari hasil uji hubungan diperoleh tingkat penggunaan terbanyak MKJP adalah oleh responden dengan umur 20 - 35 tahun sedangkan dari 28 responden yang berumur $>35$ tahun didapatkan 5 responden yang menggunakan MKJP dan 23 responden yang tidak menggunakan MKJP. Ini menunjukkan tidak ada hubungan antara umur dengan rendahnya penggunaan metode Kontrasepsi jangka panjang dimana justru yang berumur muda/ dibawah yang menggunakan MKJP dalam jumlah lebih tinggi sedangkan responden yang berumur $>35$ dengan tingkat penggunaan MKJP lebih rendah.

Berdasarkan penelitian tentang "faktor yang mempengaruhi penggunaan metode Kontrasepsi jangka panjang" oleh Sri Maryani pada tahun 2015 juga mengemukakan dalam jurnalnya bahwa tidak ada pengaruh signifikan anatara umur dengan penggunaan metode Kontrasepsi jangka panjang dan menarik kesimpulan bahwa MKJP tidak identik digunakan oleh responden yang berumur muda saja.

Namun tidak sejalan dengan hasil penelitian Amiranty (2003) menyatakan bahwa ada hubungan yang bermakna pada tiap kelompok umur dengan pemakaian MKJP. Wanita yang berusia 36-49 tahun memiliki peluang sebesar 10 kali untuk memakai MKJP dibandingkan wanita yang berusia $<35$ tahun.

Namun pada penelitian ini ditemukan bahwa sebagian besar responden yang berusia >35tahun dan 20-35 tahun lebih banyak yang memakaian non MKJP dibandingkan MKJP dan tidak ada hubungan bermakna dengan pemakaian MKJP. Hasil analisis hubungan antara umur dengan pemakaian MKJP didapatkan bahwa tidak ada hubungan yang bermakna.

\section{Hubungan antara Pengetahuan responden dengan rendahnya penggunaan metode Kontrasepsi jangka panjang.}

Dengan penggunaan MKJP akan memberikan perlindungan dari kehamilan yang lebih lama dengan efektifitas tinggi dan meningkatkan kelangsungan penggunaan alat kontrasepsi bagi peserta. Pengetahuan merupakan faktor paling dominan dalam pemilihan MKJP, Oleh karena itu, untuk meningkatkan pemakaian MKJP, petugas kesehatan pada saat konseling KB sebaiknya dilakukan sosialisasi melalui promosi dan edukasi untuk meningkatkan pengetahuan calon peserta $\mathrm{KB}$, maupun peserta KB yang menggunakan alat kontrasepsi non MKJP agar bisa beralih ke metode KB MKJP.

Tingkat pengetahuan masyarakat akan mempengaruhi 
penerimaan program $\mathrm{KB}$ di masyarakat. Studi yang dilakukan oleh Anne R Pebley dan James W Breckett (1982) menemukan bahwa "Sekali wanita mengetahui tempat pelayanan kontrasepsi, perbedaan jarak dan waktu bukanlah hal yang penting dalam menggunakan kontraseps, dan mempunyai hubungan yang signifikan anatara pengetahuan tentang tempat pelayanan dan metode kontrasepsi yang digunakan.

Wanita yang mengetahui tempat pelayanan kontrasepsi lebih sedikit menggunakan metode kontrasepsi tradisional." Pengetahuan yang benar tentang program KB termasuk tentang berbagai jenis kontrasepsi akan mempertinggi keikutsertaan masyarakat dalam program KB.Hasil Bivariat menunjukkan tidak ada hubungan antara Pengetahuan dengan rendahnya penggunaan metode Kontrasepsi jangka panjang, dimana hasil uji Chi- square dengan nilai kemakmuran $\mathrm{a}=0,05$ dimana hasil $\mathrm{p}=0,250$ yang menunjukkan $\mathrm{p}>$ atau 0,250>0,05 menunjukkan tidak ada hubungan antara tingkat Pengetahuan dengan rendahnya penggunaan MKJP.

Penelitian ini menunjukkan tidak ada hubungan pengetahuan dengan rendahnya penggunaan metode Kontrasepsi jangka panjang dimana dari hasil ujihubungan diperoleh frekuensi tingkat penggunaan MKJP hampir oleh responden pengetahuan baik maupun kurang hampir sebanding. Dimana diketahui bahwa dari 39 responden dengan pengetahuan baik, yang menggnuakan MKJP 11 responden dan yang tidak menggunakan MKJP 28 responden sedangkan dari 55 responden dengan pengetahuan kurang 10 responden menggunakan MKJP dan 45 tidak menggunakan MKJP.

Namun tidak sejalan dengan hasil penelitian Anne R Pebley dan James W Breckett (1982) yang mengatakan dalam jurnalnya bahwa tingkat pengetahuan masyarakat akan mempengaruhi penerimaan program KB di masyarakat dan mengetahui tempat pelayanan kontrasepsi, perbedaan jarak dan waktu bukanlah hal yang penting dalam menggunakan kontrasepsi, dan mempunyai hubungan yang signifikan anatara pengetahuan tentang tempat pelayanan dan metode kontrasepsi yaPengetahuan ibu tentang MKJP berhubungan dengan minat MKJP.

Berdasarkan hasil penelitian tentang "faktor-faktor yang berhubungan dengan rendahnya minat ibu terhadap penggunaan metode kontrasepsi jangka panjang" oleh Eminur pada tahun 2016 juga mengemukakan bahwa Pengetahuan menjadi dasar dalam berperilaku dan mempersepsikan sesuatu. Pengetahuan yang benar akan mempertinggi minat penggunaan Metode Kontrasepsi Jangka Panjang. 
Yusuf (2011) juga menemukan hubungan signifikan antara pengetahuan MKJP dengan penggunaan MKJP di Tanjung Batu . Ibu berpengetahuan MKJP tinggi berpeluang 2 kali lebih besar untuk menggunakan MKJP dibandingkan ibu berpengetahuan MKJP rendah.

\section{Hubungan antara Pendidikan responden dengan rendahnya penggunaan metode Kontrasepsi jangka panjang.}

Faktor pendidikan seseorang sangat menentukan dalam pola penga mbilan keputusan dan penerimaan informasi dari pada seseorang yang berpendidikan rendah (Broewer, 1993). Pendidikan juga akan mempengaruhi pengetahuan dan persepsi seseorang tentang pentingnya suatu hal, termasuk dalam perannya dalam program KB. Pada akseptor KB dengan tingkat pendidikan rendah, keikutsetaannya dalam program $\mathrm{KB}$ hanya ditujuakan untuk mengatur kelahiran.

Sementara itu pada akseptor KB dengan tingkat pendidikan tinggi, Keikutsertaannya dalam program KB selain untuk mengatur kelahiran juga untuk meningkatkan kesejahteraan keluarga karena dengan cukup dua anak dalam satu keluarga dan laki-laki atau perempuan sama saja maka keluarga kecil bahagia dan sejahtera dapat tercapai dengan mudah. Hal ini dikarenakan seseorang dengan tingkat pendidikan lebih tinggi memiliki pandangan yang lebih luas tentang suatu hal dan lebih mudah untuk menerima ide atau cara kehidupan baru.

Dengan demikian, tingkat pendidikan juga memiliki hubungan dengan pemilihan jenis kontrasepsi yang akan digunakan.

Hasil Bivariat menunjukkan ada hubungan antara Pendidikan dengan rendahnya penggunaan metode Kontrasepsi jangka panjang, dimana hasil uji Chi- square dengan nilai kemakmuran $\mathrm{a}=0,05$ dimana hasil $\mathrm{p}=0,011$ yang menunjukkan $\mathrm{p}$ $<$ atau $0,011<0,05$ menunjukkan tidak ada hubungan antara tingkat pendidikan dengan rendahnya penggunaan MKJP.

Penelitian ini menunjukkan ada hubungan pendidikan dengan rendahnya penggunaan metode Kontrasepsi jangka panjang dimana dari hasil uji hubungan diperoleh frekuensi pengunaan non MKJP tertinggi oleh responden dengan pendidikan dasar dimana responden berjumlah 45, yang menggunakan MKJP hanya 5 responden sedangkan yang non MKJP 40 responden, yang berpendidikan menengah sebanyak 42 responden yang menggunakan MKJP 12 responden yang tidak menggunakan MKJP 30 responden sedangkan pendidikan tinggi berjumlah 7 responden yang menggunakan MKJP 4 responden dan yang tidak menggunakan MKJP 3 responden. 
Sejalan dengan penelitian Lusiana Trisnawati (2016) yang berjudul "Hubungan antara pengetahuan tentaang $\mathrm{KB}$ metode kontrasepsi jangka panjang sikap ibu peserta jampersal pasca persalinan dengan penggunaan $\mathrm{kb}$ metode kontrasepsi jangka panjang di puekesmas kartasura" mengemukakan bahwa Pendidikan juga berperan penting dalam pembentukan kecerdasan manusia maupun perubahan tingkah lakunya. Pendidikan juga berarti bimbingan yang diberikan seseorang kepada orang lain terhadap sesuatu hal agar mereka dapat memahami. Hingga peneliti menarik kesimpulan Tidak dapat dipungkiri bahwa semakin tinggi pendidikan seseorang maka semakin mudah pula mereka menerima informasi. Pada akhirnya banyak pula pengetahuan yang dimilikinya. Sebaliknya jika seseorang memiliki tingkat pendidikan yang rendah maka akan menghambat perkembangan sikap seseorang terhadap penerimaan informasi.

Faktor pendidikan seseorang sangat menentukan dalam pola penga mbilan keputusan dan penerimaan informasi dari pada seseorang yang berpendidikan rendah (Broewer, 1993). Pendidikan juga akan mempengaruhi pengetahuan dan persepsi seseorang tentang pentingnya suatu hal, termasuk dalam perannya dalam program $\mathrm{KB}$. Pada akseptor KB dengan tingkat pendidikan rendah, keikutsetaannya dalam program KB hanya ditujuakan untuk mengatur kelahiran.

Sementara itu pada akseptor KB dengan tingkat pendidikan tinggi, Keikutsertaannya dalam program KB selain untuk mengatur kelahiran juga untuk meningkatkan kesejahteraan keluarga karena dengan cukup dua anak dalam satu keluarga dan laki-laki atau perempuan sama saja maka keluarga kecil bahagia dan sejahtera dapat tercapai dengan mudah. Hal ini dikarenakan seseorang dengan tingkat pendidikan lebih tinggi memiliki pandangan yang lebih luas tentang suatu hal dan lebih mudah untuk menerima ide atau cara kehidupan baru. Dengan demikian, tingkat pendidikan juga memiliki hubungan dengan pemilihan jenis kontrasepsi yang akan digunakan.

\section{Hubungan antara Sosial ekonomi responden dengan rendahnya penggunaan metode Kontrasepsi jangka panjang.}

Pemakaian MKJP tertinggi pada kelompok PUS dengan biaya pemasangan $\mathrm{KB}$ yang gratis dan tidak ada hubungan bermakna dengan pemakaian MKJP. Hukum pasar menunjukkan bahwa pelayanan kontrasepsi yang lebih baik dengan harga yang tepat akan menarik lebih banyak klien.

Pasangan suami istri akan mempunyai keinginan atau motivasi untuk membatasi kehamilan dalam 
bentuk pemakaian alat kontrasepsi yang bersangkutan jika biaya atau pengorbanan yang harus mereka keluarkan untuk tujuan ini relatif kecil atau tidak ada sama sekali. Hasil penelitian ini tidak sejalan dengan hasil penelitian Kemala (2002) menyatakan ada hubungan antara biaya pelayanan KB dengan penggunaan MKJP dengan $p$ value 0,001 .

Hasil Bivariat menunjukkan ada hubungan antara Sosial ekonomi dengan rendahnya penggunaan metode Kontrasepsi jangka panjang, dimana hasil uji Chi- square dengan nilai kemakmuran $\mathrm{a}=0,05$ dimana hasil $\mathrm{p}=0,038$ yang menunjukkan $\mathrm{p}<$ atau $0,038<0,05$ menunjukkan tidak ada hubungan antara tingkat Sosial ekonomi dengan rendahnya penggunaan MKJP.

Penelitian ini menunjukkan ada hubungan Sosial ekonomi dengan rendahnya penggunaan metode Kontrasepsi jangka panjang dimana dari hasil uji hubungan diperoleh frekuensi penggunaan MKJP tertinggi oleh responden dengan sosial ekonomi menengah ke atas. Dimana dari 53 responden sosial ekonomi menengah atas 16 responden menggnakan MKJP dan 37 non MKJP sedangkan responden sosial ekonomi menengah ke bawah sebanyak 41 responden, yang menggunakan MKJP hanya 5 responden dan 36 non MKJP.

Menurut Easterlin (1975) dalam Bakir (1984) menyatakan bahwa pasangan suami istri akan mempunyai keinginan atau motivasi untuk membatasi kehamilan dalam bentuk pemakaian alat kontrasepsi yang bersangkutan jika biaya atau pengorbanan yang hares mereka keluarkan untuk tujuan ini relatif kecil atau tidak ada sama sekali.

Hasil penelitian ini tidak sejalan dengan hasil penelitian Kemala (2002) menyatakan ada hubungan antara biaya pelayanan KB dengan penggunaan MKJP dengan $p$ value 0,001 .

Berdasarkan penelitian yang di lakukan oleh Eminur pada tahun 2016 tentang "faktor-faktor yang berhubungan dengan rendahnya minat ibu terhadap penggunaan metode kontrasepsi jangka panjang" mengemukakan bahwa Pendapatan atau sosial ekonomi berhubungan dengan minat MKJP. Biaya pemasangan IUD jenis nova-T dengan daya proteksi 8 tahun di BPS Sri Romdati adalah Rp 350,000. Sementara itu biaya pemasangan implan dengan daya proteksi 3 tahun adalah Rp 150.000,00. Jumlah biaya yang harus dibayarkan tersebut tentunya cukup tinggi bagi mereka yang berpendapatan di bawah 1,5 juta sehingga ibu yang secara ekonomi.

Sudah tidak mampu mengakses biaya pemasangan MKJP akan cenderung tidak berminat menggunakan MKJP. Hasil penelitian ini sejalan dengan hasil penelitian Nasution (2011) yang juga 
menemukan bahwa tingkat pendapatan berpengaruh pada pemilihan MKJP $(\mathrm{p}=0,000)$. Ibu yang berpenghasilan rendah lebih beresiko 0,73 kali untuk tidak memilih menggunakan MKJP $(\mathrm{OR}=0,73)$. Pemerintah sebenarnya telah menggratiskan biaya pemasangan MKJP untuk seluruh pasien BPJS. Sayangnya tidak semua pasien di BPS Sri Romdhati adalah pemegang kartu BPJS.

Hubungan antara Dukungan keluarga dam dukungan pasangan responden dengan rendahnya penggunaan metode Kontrasepsi jangka panjang.

Dukungan suami dan keluarga sangat diperlukan untuk pengambilan keputusan dalam ber KB karena kenyataan yang terjadi dimasyarakat bahwa apabila suami dan keluarga tidak mengijinkan atau tidak mendukung hanya sedikit ibu yang berani untuk tetap memasang alat kontrasepsi tersebut.

Dukungan suami dan keluarga berpengaruh besar dalam pengambilan keputusan untuk menggunakan atau tidak dan metode apa yang digunakan. Bentuk dukungan yang diberikan kepada pasangan dapat berupa mengingatkan untuk kontrol, mengantar untuk mendapatkan pelayanan $\mathrm{KB}$, menyediakan dana serta memberikan persetujuan terhadap alat kontrasepsi yangdigunakan pasangannya. Semakin banyak ibu yang mendapat persetujuan dan dukungan dari suami untuk menggunakan MKJP maka diharapkan bahwa calon akseptor akan lebih banyak yang menggunakan MKJP.

Hasil Bivariat menunjukkan ada hubungan antara Dukungan keluarga dengan rendahnya penggunaan metode Kontrasepsi jangka panjang, dimana hasil uji Chisquare dengan nilai kemakmuran $\mathrm{a}=0,05$ dimana hasil $\mathrm{p}=0,001$ yang menunjukkan $\mathrm{p}<$ atau $0,001<0,05$ menunjukkan tidak ada hubungan antara Dukungan keluarga dengan rendahnya penggunaan MKJP.

Penelitian ini menunjukkan ada hubungan dukungan keluarga dengan rendahnya penggunaan metode Kontrasepsi jangka panjang dimana dari hasil uji hubungan diperoleh frekuensi penggunaan MKJP tertinggi oleh responden dengan dukungan keluarga dimana diketahui bahwa dari 43 responden dengan keluarga yang mendukung, 16 responden menggunakan MKJP dan 27 non MKJP sedangkan keluarga yang tidak mendukung sejumlah 51 responden hanya 5 responden yang menggunakan MKJP dan 46 non MKJP.

Dukungan suami dan keluarga mempunyai hubungan yang bermakna dengan penggunaan MKJP dengan nilai ( $\mathrm{p}=0,007)$ kecenderungan bahwa ibu yang mendapatkan dukungan suami 3.372 kali akan menggunakan MKJP dibandingkan dengan ibu yang kurang mendapat dukungan suami. 
Hasil ini bertentangan dengan penelitian Kusumaningrum (2008) yang menyatakan bahwa dukungan pasangan tidak memiliki hubungan yang bermakna terhadap pemilihan jenis kontrasepsi. Menurut BKKBN (2011) dukungan suami sangat diperlukan untuk pengambilan keputusan dalam ber KB karena kenyataan yang terjadi dimasyarakat bahwa apabila suami tidak mengijinkan atau tidak mendukung hanya sedikit ibu yang berani untuk tetap memasang alat kontrasepsi tersebut.

Dukungan suami berpengaruh besar dalam pengambilan keputusan untuk menggunakan atau tidak dan metode apa yang digunakan. Bentuk dukungan yang diberikan kepada pasangan dapat berupa mengingatkan untuk kontrol, mengantar untuk mendapatkan pelayanan $\mathrm{KB}$, menyediakan dana serta memberikan persetujuan terhadap alat kontrasepsi yang digunakan pasangannya. Semakin banyak ibu yang mendapat persetujuan dan dukungan dari suami untuk menggunakan MKJP maka diharapkan bahwa calon akseptor akan lebih banyak yang menggunakan MKJP.

\section{PENUTUP}

\section{Kesimpulan}

Berdasarkan penelitian dan hasil pembahasan yang di lakukan mak dapatdisimpulkan sebagai berikut :

Tingkat umur responden PUS di wilayah kerja Puskesmas Anreapi
Berdasarkan penelitian yang di lakukan oleh Efi Sudiarti pada tahun 2013 tentang 'faktor-faktor yang berhubungan dengan rendahnya pemakaian metode kontrasepi jangka panjang pada pasangan usia subur (PUS)" menemukan bahwa pemakain metode kontrasepsi jangka panjang pada kelompok responden yang mendapat dukungan kuat dari keluarga dan tidak ada hubungan yang bermakna dengan pemakaian metode kontrasepsi jangka panjang. Hasil penelitian ini sejalan dengan penelitian pembayun (2003) menyatakan tidak ada hubungan bermakna antara dorongan lingkungan dengan pemakaian kontrasepsi mantap.

Penelitian yang di lakukan oleh Efi Sudiarti menemukan bahwa pemakaian MKJP tertinggi pada kelompok responden yang mendapatkan dukungan kuat dari suami. Hasil penelitian ini sejalan dengan dengan penelitian yang di lakukan oleh Kartika (2011) dan Fienalia (2011) yang menyatakan bahwa terdapat hubungan signifikan antara dukungan suami dengan pemilihan metode kontrasepsi jangka panjang.

menunjukkan bahwadari 94 responden yang berusia 20 - 35 tahun sebanyak 66 responden ( 70,2 $\%$ ) dan yang berusia> 35 sebanyak 28 responden $(29,8 \%)$.

Tingkat Pengetahuan responden ada yang berpengetahuan 
baik dan berpengetahuan kurang menunjukkan bahwa dari 94 responden, yang berpengetahuan baik sebanyak 39 responden atau $(41,4 \%)$ dan yang berpengetahuan kurang sebanyak 55 responden atau $(58,6 \%)$.

Tingkat Pendidikan responden bervariasi sekolah dasar sampai perguruan tinggi menunjukkan bahwa dari 94 responden, yang responden dengan pendidikan rendah sebanyak 45 responden atau $(47,9 \%)$, dengan pendidikan menengah sebanyak 42 responden atau $(44,7 \%)$ dan dengan pendidikan tinggi sebanyak 7 responden atau $(7,4 \%)$.

Tingkat sosial ekonomi responden terdiri dari ekonomi menengah atas dan menengah bawah menunjukkan bahwa dari94(56,3\%) responden, responden dengan sosial ekonomi menengah ke atas sebanyak $53(43,7 \%)$.

Tingkt dukungan keluarga ada responden yang mendukung dan ada pula yang tidak mendukung menunjukkan bahwa dari 94 responden, responden dengan keluarga yang mendukung sebanyak 43.

\section{Saran}

Berdasarkan hasil penelitian dan analisa data faktor faktor yang berhubungan dengan rendahnya penggunaan MKJP di Puskesmas Anreapi kabupaten Polewali Mandar penulis menyarankan.

\section{Untuk Puskesmas}

\begin{abstract}
Kepada petugas puskesmas Anreapi Kecamatan Polewali Mandar agar dapat meningkatkan upaya upaya penyuluhan khususnya pentingnya penggunaan MKJP dan peningkatan kesadaran akses informasi oleh petugas kesehatan dan memberikan pelayanan yang sesuai dengan yang diharapkan.
\end{abstract}

\section{Untuk institusi Pendidikan}

Proses belajar mengjar lebih ditingkatkan dan hendaknya pendidikan lebih memihak pada proses yang dialami masyarakat sehingga ilmu pengetahuan yang diperoleh oleh peserta didik dapat dengan mudah diaplikasikan dilingkungan masyarakat.

\section{Untuk Profesi Bidan}

Pentingnya usaha peningkatan pengetahuan PUS tentang MKJP. Usaha peningkatan ini dilakukan dengan melakukan penyuluhan di Puskesmas Anreapi

Kecamatan Polewali Kabupaten Polewali Mandar.

\section{Bagi mahasiswa}


Menambah pengetahuan dan keterampilan dalam memberikan informasitentng MKJP. Perlunya dilakukan penelitin dalam lingkup yang lebih luas sehinggahasil penelitian dapat diaplikasikan dalam faktor yang berhubungan dengan rendahnya penggunaan MKJP. Peningkatan keterampilan

Mahasiswi agar akses informasi dan pelayanan yang diberikan sesuai dengan yang diharapkan.

\section{DAFTAR PUSTAKA}

AlimulHidayat. (2007).

MetodePenelitianKebidananda nTeknikAnalisis

Data.Surabaya Salemba.

Abdul Bari Saifuddin.(2010). BukuPanduanParktisPelayanan KesehatanMaternalNioatal.Jak arta

:PT.BinaPustakaSarwonoPrawi rahardjo.

Amiranty, M. (2003).Faktor-Faktor yang berhubungandenganPemakaian
MetodeKontaseosiJangkaPanja

ngpadaAkseptor KB di Propinsi Maluku dan Papua padaTahun 2001 (Analisis Data SekunderSosialEkonomiNasio mal

2001).(Skripsi).Depok.Universi tas Indonesia.

E-JurnalPustakaKsehatan.Vol. 3 (No.1), Januari 2015.

Ekarini, Sri. (2008). AnalisisFaktorFaktor yang BerpengaruhTerhadapPartisipa siPriadalamKeluargaBerencana di KecamatanBoyalali.Oktober, 2011. Program PascaSarjana FKM UNDIP.

Fienslia, Alus Rainy. (2012). FaktorFaktor yang BerhubungandenganPenggunaa nMetodeKontrasepsiJangkaPan jang (MKJP) di Wilayah KerjaPuskesmasPancoran Mas Kota DepokTahun 2011.Depok, Skripsi FKM UI.

HanafiHartanto. (2004).

KeluargaberencanadanKontras epsi.Jakarta :PustakaSinarMandiri.

Hidayat,

A. (2007). RisetKeperawatandanTeknikPe nulisanIlmiah. Jakarta: SalembaMedika 
Isnar, Y.A, dkk. (2008).

PeningkatanMutuSosialisasi

KB MKJP di

PusekesmasHarapan

Raya.PekanBAru, Riau.

FakultasKedokteranUniversitas

Riau.

\section{KKBPK,}

(2017).PeningkatanAksesdanK ualitasPelayan KB. Bandung.

Prawiharjo, Sarwono.(2014).Ilmu

Kebidanan.Jakarta: Yayasan

Bina Pustka Sarwono

Prawiharjo.

Saryono.

(2011).

MetodologiPenelitianKualitatif

dalamKesehatan, Yogyakarta:

NuhaMedika

SoekidjoNotostmodjo, (2010).

EtikadanHukumKesehatan.Jak

arta :RinekaCipta.

Susenas.(2009 dan

2010).PenyusunanKondisiSosi

alEkonomiJawa Barat.Jawa

Barat. 